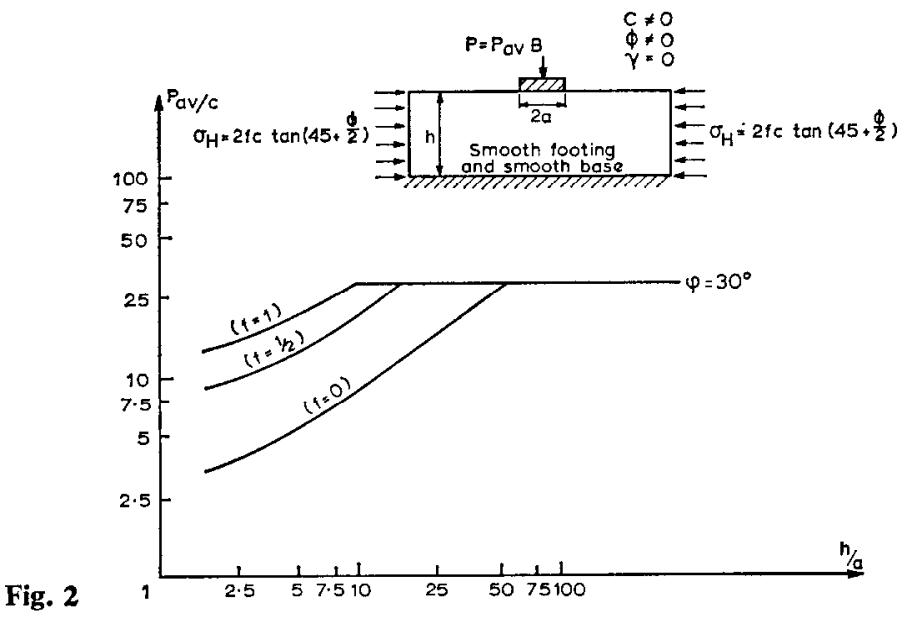

the average vertical stress on the footing which corresponds to an assumed average horizontal stress of $\sigma_{\mathrm{H}}^{\prime}$, with similar definitions for $P^{\prime \prime}{ }_{\mathrm{av}}$ and $\sigma^{\prime \prime}{ }_{\mathrm{H}}$. Then it may be shown that

$$
\frac{P_{a v}^{\prime}+c \cot \phi}{\sigma_{\mathrm{H}}^{\prime}+c \cot \phi}=\frac{P_{\mathrm{av}}^{\prime \prime}+c \cot \phi}{\sigma_{\mathrm{H}}^{\prime \prime}+c \cot \phi}
$$

Equation (1) can be used to relate Mandel and Salençon's numerical solution with the Writer's analytic solution. A comparison is shown in Fig. 1. Equation (1) can be also used to calculate the failure loads corresponding to an average horizontal stress which lies between the two extremes considered by Mandel and Salençon

$$
\sigma_{\mathrm{H}}=2 c \tan \left(\frac{\pi}{4}+\frac{\phi}{2}\right)
$$

and the Writer $\sigma_{\mathrm{H}}=0$. This has been done in Fig. 2 for the particular case of $\phi=30^{\circ}$.

\title{
REFERENCES
}

Booker, J. R. (1972). A method of integration of the equations of plasticity for a weightless cohesive frictional material. Q.Jnl Mech. Appl. Math. 25, Part 1.

\section{Apparatus for measuring volume change suitable for automatic logging}

ROWLANDS, G. O. (1972). Géotechnique 22, No. 3, 525-526.

\section{P. Darley, Earthworks and Foundations Division, Transport and Road Research Laboratory}

The Author has described a simple method for automatically recording volume changes in the triaxial test based on the Bishop self-compensating mercury constant-pressure unit and using a linear displacement transducer.

The Writer has developed a similar device shown in Fig. 1. Unlike the device described by Rowlands the apparatus has the advantage in that it uses a single spring which gives twice the sensitivity. Pot $B$ is fixed while pot $A$ is suspended from the spring by the core of the linear displacement transducer. The use of hook joints in the suspension facilitates the axial alignment of the core within the transducer body and reduces the effect on the core of lateral movements of the pot. 
Fig. 1. Schematic diagram of volume measuring

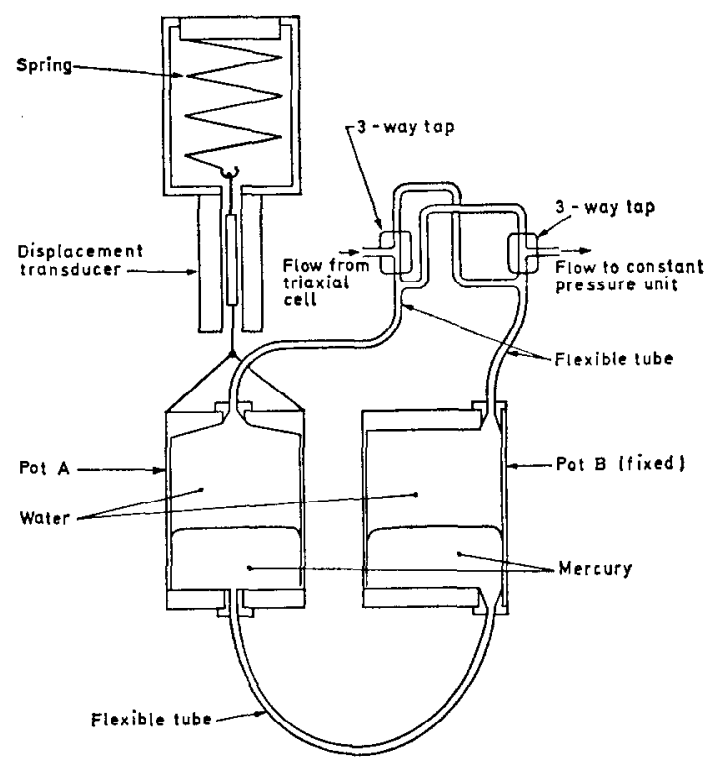
system

To maintain the mercury levels a spring of stiffness $196 \mathrm{~N} / \mathrm{m}$ is used with pots of $63.5 \mathrm{~mm}$ internal dia. This gives a theoretical sensitivity of $0.63 \mathrm{~mm}$ change in spring length per mlitre of volume change.

The instrument has been tested for stability for periods of up to $48 \mathrm{~h}$ and gave readings within \pm 0.015 mlitre. It has also been calibrated against a paraffin volume change indicator at flow rates of $0.1 \mathrm{mlitre} / \mathrm{min}$ and $0.5 \mathrm{mlitre} / \mathrm{min}$. The calibrations showed the device to be accurate to within \pm 0.05 mlitre and there was no significant change of calibration with rate of flow.

Using a $\pm 7.5 \mathrm{~mm}$ transducer a volume of 24 mlitre can be measured. If it is required to measure larger volumes a tap system as shown in Fig. 1 can be included to reverse the direction of flow through the instrument.

During testing considerable difficulty was encountered in de-airing the prototype. The pots were therefore modified as shown so that the mercury could be pumped into pot B which is then rotated to a horizontal position allowing a free flow of water through the device.

At present the device appears to offer a simple and convenient method for automatically recording volume changes with sufficient accuracy and stability for routine testing. Further evaluation of the device for use with the triaxial test is currently being done at the Laboratory.

\section{The increase in bearing capacity resulting from consolidation}

TAYLOR, P. W. and OOI, T. A. (1971). Géotechnique 21, No. 4, 376-389.

\section{S. B. Bhide and P. N. Sundaram, Indian Institute of Technology, Bombay}

The Authors have presented an excellent analysis of the effect of consolidation on increase in bearing capacity of soft clays and cite examples of preloading of oil storage tanks to achieve an increase in bearing capacity of such soft clays. 